\title{
Construction Of Gender Identity Through Written Discourse
}

\author{
Kaleem Raza Khan \\ \& \\ Shumaila Shafket Ali \\ Department of English \\ University of Karachi
}

\begin{abstract}
Writing is a reflection of an individual's thought patterns and can manifest different forms of identity: personal, religious, cultural, political, and above all gender identity. A closer look at any text not only helps discover the origin of the writer, but can also reveal his/her gender, which is projected in the text. Using Butler's notion of 'performing gender', the study aims to explore gender identity constructed through the written discourse of male and female students by analyzing the differences and/or similarities in their writing. The categories considered for analysis include: selection of the topic projecting the background knowledge of the writer (reflecting how widely read he/she is), lexical and syntactic choices, degree of grammatical accuracy, degree of modality, element of personalization, and informative vs. involved style, which is evident through the text that is produced. The data of the study are based on students' essays that they were made to write in the CSS preparatory classes conducted under the Students' Guidance Counselling and Placement Bureau and Overseas Examination, University of Karachi. Being a qualitative study, the sample size chosen was limited to the essays by 30: fifteen produced by male and fifteen by female students. The written samples were selected on the basis of stratified sampling, dividing the samples into two homogenous groups, to do a comparative analysis. The findings of the study reveal significant differences in the writing style of both the genders, which proves that the construction of gender identity is not restricted to oral communication but is also observed in writing.
\end{abstract}

Keywords: Identity Construction; Gender Identity; Performing Gender; Gender Ideology.

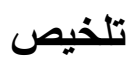

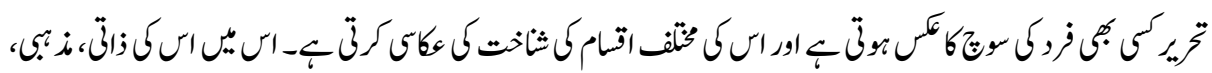

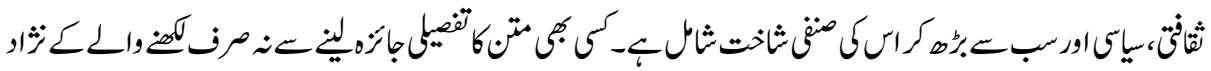

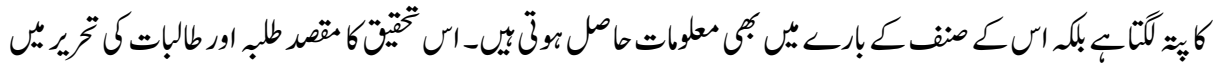

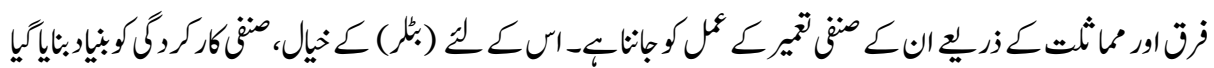

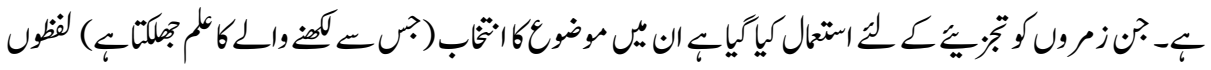

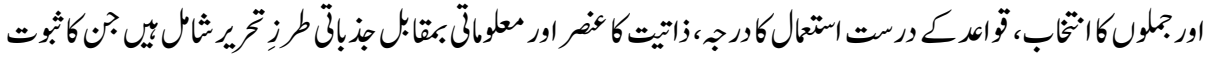




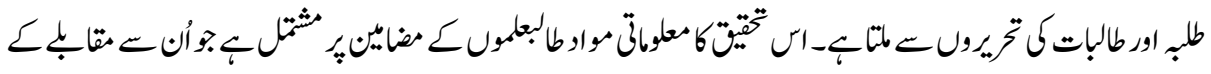

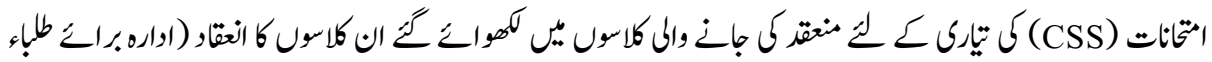

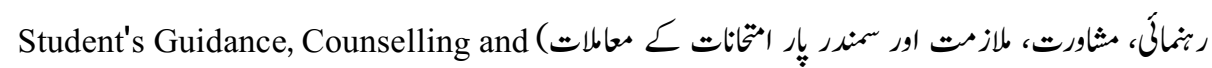

$$
\begin{aligned}
& \text { Placement Bureau \& Overseas Examination }
\end{aligned}
$$

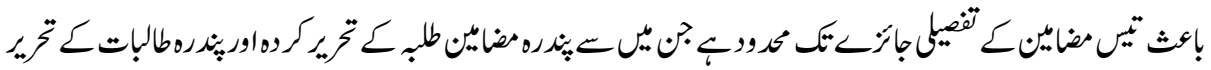

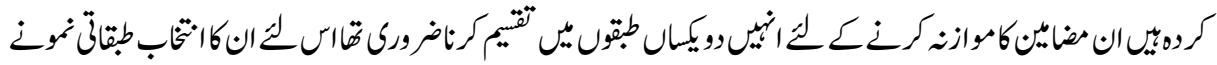

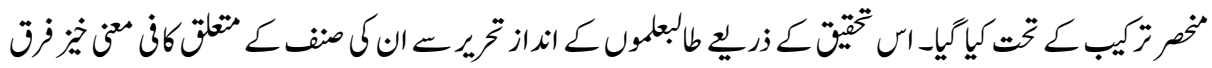

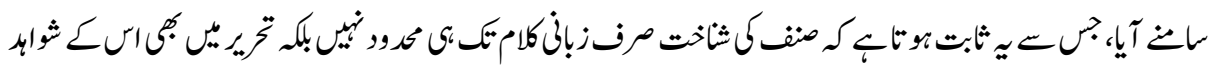

$$
\begin{aligned}
& \text { متثبي }
\end{aligned}
$$

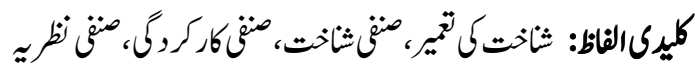

\section{Introduction}

Language users engaged in both spoken and written discourse besides using language for communication are also engaged in constructing different forms of identity ranging from personal to cultural and gender being one of the forms of socio-cultural identity is also a part of this process of identity construction. The construction of gender identity does not always involve socio-cultural dimensions; it has its roots in psychology as well. It can be said that gender is the socio-cultural as well psychological orientation of the self; one is not born as a male or a female but becomes one through 'performing gender'. The concept of gender 'performativity' introduced by Butler (1990) rests on the belief that gender does not exist in itself, it is performed through one's behavior, actions and above all through the use of language. Among the various differences between spoken and written discourse, one major difference is the presence of explicit identity markers in speech which cannot be traced in writing. One such explicit identity marker is the accent and the other is the voice of speakers; the former may help discover their ethno-linguistic background while the latter reveals their gender identity and their age group to some extent. This does not mean that no such process of identification is possible in written discourse. Although there are enough clues available in writing to uncover different types of identity (political, socio-cultural, religious, ethno-linguistic, national, gender), they are embedded within the text and require rigorous linguistic, to be more precise, textual analysis. 
The focus of the current study is on uncovering the gender identity of the writers, in this case students preparing for the CSS examination, focusing on the essays they wrote in their CSS preparatory classes.

\section{Research Questions}

1. How do the female and male students construct their gender identity through writing?

2. What gender differences/similarities are found in the writing style of female and male Pakistani students at tertiary level?

\section{Literature Review}

Research on English language learners' linguistic skills, particularly writing skills, has been the area of interest for language teachers and psycholinguists for several decades. However, research on second language acquisition (SLA) is not just undertaken to formulate theories of SLA but is also directed towards tracing gender identities for understanding gender ideology in order to improve language pedagogy. With reference to gender differences in writing, ample research is conducted in EFL and ESL settings around the globe (Berninger, 2008; Browne, 1994; Kanaris, 1999; Morris, 1998; Swann, 1992). Since language learning is not just a cognitive process but a social process as well, this socio-cognitive process cannot be understood without exploring gender identities negotiated through language. Although there is enough research evidence available for exploring gender differences in writing, most of the research focuses on measuring the performance of the two genders through teachers' assessment and a great deal of such research is related to primary and secondary level students' work. (Pajares \& Valiante, 2001; Peterson, 1998; 2002; Peterson \& Kennedy, 2006; Roulis, 1995). One such study focusing on gender differences at secondary level, for instance, is by Jones and Myhill (2007), who investigated gender differences in secondary school children's writing at sentence and text level. This study which forms the part of a large scale study based on a two year project is unique in the sense that it did not only focus on the quantitative analysis of the written samples of students but through follow-up interviews also elicited the students' responses on the process of writing they were engaged in. It is the first phase of the project, however, that is reported in this study. Being a large scale research, the sample was based on 718 pieces of writing including both narrative and persuasive produced by both the genders. The findings of the study reveal significant differences between the two genders showing boys as better writers than girls in certain aspects, including, paragraph competence, strong conclusion, coherence, etc.

There is some research on the relationship between gender and writing at tertiary level as well (Deming \& Gowen, 1990; Earl-Novell, 2001; Saeed, Ramazan, Gujjar, \& Iqbal, 
2011). Focusing on the evaluation of men and women ESL academic writing at the University of Melbourne, Waskita (2008) analyzed three sets of assignments by both the gender groups focusing on three categories: syntactic complexity, the process of integrating cited information, and the presentation of arguments. The results of the study showed significant differences between men and women in all three areas of academic writing. The study revealed that women produce more complex sentences, are better in terms of presenting arguments and use paraphrasing more than men for citing information.

Following Waskita (2008), Shirzad, Musavi, Atmani, Ahranjani, and Iraji (2013) conducted a study to explore gender differences in EFL academic writing by analyzing 25 M.A theses: 10 produced by male and 15 produced by female students of Linguistics. The study highlights significant differences between male and female academic discourse particularly with reference to syntactic complexity. The findings of the study showed that female writers used more complex syntactic structures as compared to male writers in academic writing and were more organized than the male writers which can be attributed to the female writers' higher level of proficiency in academic writing in English.

The current study is different from the literature cited in this section for two reasons. Firstly, it does not aim to make any evaluative judgments based on superiority of one gender over the other, but exclusively focuses on locating diversity in terms of the writing styles of both the genders. Secondly, this is for the first time that the writing skills of Pakistani students, who intend to appear in the CSS examination, are made the focus of the study to locate gender differences.

\section{Methodology}

The study being rooted in qualitative paradigm is based on the analysis of the essays produced by the students attending CSS preparatory classes organized by the Students' Guidance, Counselling and Placement Bureau and Overseas Examination, University of Karachi. The CSS preparatory classes are organized every semester to facilitate not only students of the University of Karachi but also students from other institutions who intend to take the Civil Superior Services (CSS) examination. The course offers guidance on all compulsory subjects that are part of the CSS syllabus.

The sample size chosen for this study was based on 30 essays: 15 by female and 15 by male students. The selection of essays for analysis was based on stratified sampling as equal number of samples was selected to represent both the genders. However, for selecting 15 essays produced by each gender, simple random sampling technique was employed so that every student's work can get a chance of being selected for the study, which is in accordance with the probability sampling under which comes both, simple random and stratified sampling procedures. For selecting the sample essays through

random sampling technique, lottery method was used. Once the names were selected 
through lottery method, these students' essays were analyzed to discover if there are significant differences in their writing style.

It is pertinent to mention here that the essays selected for analysis were produced in the second week of the CSS preparatory classes as part of the classroom activity, so the data gathered for this study is natural. Since the students were made to write these essays before they were actually taught essay writing in this course, whatever they produced reflected their level of writing at that point in time. Essay writing was chosen because it comes under academic writing which is the focus of our study. Besides this, other than the English Compulsory paper of 100 marks in the CSS examination, there is an additional 100 marks compulsory paper based on testing students' writing skills through this genre. There was yet another reason for choosing essay writing. It is part of the English compulsory syllabus at all levels (primary, secondary, and tertiary) in Pakistan. So, it was not a new genre for them; they already had some exposure to essay writing. Engaging the students in essay writing before teaching writing skills in the Course helped us as English language teachers as we became aware of their weak and strong areas, including some of the wrong concepts they had acquired through being exposed to faulty teaching practices. This awareness about students' writing skills helped us plan our sessions accordingly. There were six topics that were given to the students out of which they had to select one to write an essay. The topics were selected from the previous CSS examination papers to see how well students can present their arguments and how much effort is needed to help them in this area.

\section{Data Analysis}

The data for the current study are analyzed using some of the categories proposed by Waskita (2008) and Shirzad et al., (2013). However, the analysis is not just confined to the categories these researchers employed in their study. Some additional categories have also been incorporated for analyzing the essays. There were seven categories in all that were considered for analysis to see if there are similarities and/or differences between the male and female writing. The categories used for analysis include: selection of the topic indicating the background knowledge of the writer (reflecting how widely read she/he is), lexical choices, syntactic choices, degree of grammatical accuracy, degree of modality, element of personalization, and informative vs. involved style, which is evident through the text that is produced.

\section{Topic Choice and Schematic Knowledge}

Beginning with the topic choice, not much difference emerged as all the six topics given to the students belonged to the genre of argumentative essay. The topics related to economic prosperity, gender equality and free speech were selected by both the genders. 
However, the other three topics (revolving around human rights, public office, and Pakistan's natural resources) were not selected by any female student. Although these three topics that were selected by only male students were equally argumentative, no female student selected them for writing the essay. One reason could be the need for more factual details for writing on these topics requiring an informative rather than an interactional or involved style of discourse and informative style of writing is a characteristic feature of male writing; female writing style is considered to be involved or interactional in nature. Moreover, the male students' selection of the topics that required factual details also indicates their schematic knowledge based on their reading. The analysis of the topic choice also gives a glimpse of the differences in their reading habits and the nature of topics they are interested in reading and writing about.

\section{Lexical Choices}

Selection of the topic is not the sole criterion for locating gender differences in writing. Another way of discovering the construction of gender through writing is through focusing on the lexical choices, particularly the choice of adjectives by both the genders in their written discourse. Table: 1(a) presents the details regarding gender differences in the lexical choices in writing:

Table: $1(\mathbf{a})$

\begin{tabular}{|l|c|c|}
\hline $\begin{array}{c}\text { Frequency and nature of lexical } \\
\text { choices }\end{array}$ & Female Students & Male Students \\
\hline Number of Attributive Adjectives & 261 & 283 \\
\hline Number of Predicative Adjectives & 74 & 52 \\
\hline
\end{tabular}

Research studies on gender differences in writing report the use of attributive adjectives in males' writing more than predicative adjectives. Moreover, it is also observed that the use of attributive adjectives is higher in non-fiction writing in males as compared to their usage in female writers. The essays analyzed for this study, however, reveal marginal difference in the use of attributive adjectives, which is evident from the data presented in Table: 1(a). Although the number of attributive adjectives used by the male students is five times more than the use of predicative adjectives, there is very little difference in the use of attributives as far as gender variable is concerned. Nevertheless, there is a significant difference in the frequency of the use of predicative adjectives according to the data given in Table: 1(a). The female students used 22 more predicative adjectives in their essays as opposed to the male students. 


\section{Syntactic Choices}

With regard to the syntactic complexity in academic writing, previous research studies on gender differences show women using more complex structures as compared to men (Shirzad et al., 2013; Younger, Warrington, \& Williams, 1999). In order to test the validity of the previous research findings, the selected samples of students' essays were analyzed to determine the syntactic complexity. Table 1(b) given below presents the findings based on gender differences in terms of syntactic complexity.

Table: 1 (b)

\begin{tabular}{|l|c|c|}
\hline \multicolumn{1}{|c|}{ Syntactic choices } & Female Students & Male Students \\
\hline Simple sentences & 180 & 120 \\
\hline Compound sentences & 210 & 283 \\
\hline Complex sentences & 173 & 95 \\
\hline Complex compound sentences & 154 & 80 \\
\hline
\end{tabular}

The data presented in Table: 1(b) shows that overall female students' writing display signs of more syntactic complexity as compared to male students, as the frequency of usage of complex and complex compound sentences is almost twice as high as the frequency of usage of these structures in the male-authored essays. This difference, however, cannot be attributed to better writing skills on the part of the female students, as there were quite a few errors in their formation of complex and complex compound sentences. Furthermore, the use of simple sentences does not necessary imply limited proficiency in the language. It could be the individual style of the writer, as is the case with some fiction as well non-fiction writers.

Besides focusing on the sentence type to figure out the syntactic complexity, another way to measure syntactic complexity is to count the frequency of cohesive devices and the nature of these devices used in the text. The data based on the frequency and types of cohesive devices are given in table 1(c).

Table: 1 (c)

\begin{tabular}{|l|c|c|}
\hline $\begin{array}{c}\text { Frequency and type of cohesive } \\
\text { devices used in the essays }\end{array}$ & $\begin{array}{c}\text { Female Students' } \\
\text { essays }\end{array}$ & Male Students' essays \\
\hline Conjunctive ties & 371 & 380 \\
\hline Referential ties & 216 & 225 \\
\hline
\end{tabular}

In contrast to the earlier research on gender differences in the use of cohesive devices, the current study shows a different pattern. The data does not reveal any significant difference between the conjunctive ties used as the female students used 371 while the male students used 380 conjunctive ties. The same pattern is found in case of referential 
ties as given in Table: 1(c). These findings are different from previous research findings in another sense for the male students in this study used 155 more conjunctive ties as opposed to referential ties, which is in sharp contrast to the findings by Shirzad et al., (2013) showing that men tend to use referential ties more than conjunctive ties in their writing. The analysis of the essays also revealed that female students had the tendency to use longer paragraphs than the male students and included more specific details.

\section{Degree of Grammatical Accuracy}

The degree of grammatical accuracy can be determined by taking into account the frequency and type of errors found in a text. The higher the frequency of errors the lower is the degree of grammatical accuracy. Gender differences in errors produced by male and female students have been explored in several research studies (Boroomand, Abusaeedi, \& Asghar, 2013; Chen, 1996; Chiu, 2008). Although this study does not focus on error analysis, it does take into account differences in the frequency and the nature of errors produced by each gender so that this information can be utilized to bring the required changes in one's pedagogical practices while teaching English language. Table: 1(d) presents the numerical data based on the errors produced in the essays written by both the male and the female students. The errors are divided into six categories according to their nature.

Table: 1 (d)

\begin{tabular}{|l|c|c|}
\hline \multicolumn{1}{|c|}{ Type and frequency of errors } & Female Students & Male Students \\
\hline Error in subject-verb agreement & 28 & 42 \\
\hline Error of omission & 16 & 17 \\
\hline Error of addition & 30 & 55 \\
\hline Error of substitution & 08 & 19 \\
\hline Spelling errors & 23 & 36 \\
\hline Unnecessary capitalization & 08 & 50 \\
\hline
\end{tabular}

As given in Table: 1(d), both male and female students' written samples exhibit a variety of errors ranging from mechanical (spelling and capitalization) to grammatical inaccuracies displaying problems in subject-verb agreement, and other areas of discourse. Nevertheless, the frequency of errors in female students' writing is found to be low as compared to the errors found in male students' essays. Except one category which deals with error of omission, the other categories exhibit significant gender differences and the most obvious difference is found in the last category mentioned in Table 1(d) dealing with the use of unnecessary capitalization. As evident from the data provided in the above table, male students used unnecessary capitalization 4 times more than the female students. The tendency to capitalize words may be indicative of the desire to assert power or control, which may be considered a true representation of male psychology. This 
seems to be in accordance with Butler's notion of gender 'performativity' which rests on the belief that our actions play a decisive role in shaping our gender identity. If words are seen as acts, language can also be considered a source of performing gender.

Moreover, the data presented in Table 1(d) carries the implication that females tend to use standard forms more than men and are more conscious of using correct language which in turn is suggestive of their efforts to strictly adhere to rules. The low frequency of spelling errors on the part of female students could also be reflective of their extensive reading practice. It has been proved through research on reading that good readers are also good spellers (Chambers, 1992; Krashen, 1989; Taha, 2006). It is pertinent to mention here that significant differences were noted not only in the frequency of errors but also in the nature of errors in some of the categories, which may be associated with the gender of the students whose work is analyzed for this study. For example, the female students displayed the tendency to add verb 'be' which led to ungrammaticality in otherwise active sentences. For example, one of the female students wrote in her essay "It will be increase their economic prosperity." instead of writing "It will increase their economic prosperity."

\section{Degree of Personalization}

The degree of detachment or involvement in the text can be judged through the element of personalization used in the text, which in turn can be determined through the use of first person pronouns. There are obvious gender differences in this area of discourse indicating that some of the differences can be safely attributed to the gender of the writer. The frequency of usage of the plural first person pronoun 'we' by female students is double the frequency of usage by the male students, which is evident from the data presented in Table 1(e).

Table: 1 (e)

\begin{tabular}{|l|c|c|}
\hline $\begin{array}{c}\text { Frequency and nature of } \\
\text { first person pronouns }\end{array}$ & Female Students & Male Students \\
\hline First person singular 'I' & 2 & Zero \\
\hline First person plural 'we' & 98 & 49 \\
\hline
\end{tabular}

The high frequency of occurrence of the first person plural pronoun 'we' indicates the females' tendency to involve the readers which is in accordance with the previous research findings implying that female writers use high involvement strategy through the use of 'we', while male writing is more ego-centric as they use singular first person pronoun more often than females in non-fiction writing. Nevertheless, the essays that were analyzed for this study do not carry even a single ' $\mathrm{I}$ ' in the essays the male writers produced. Instead there were two instances of 'I' found in one of the female students' essay which may be the 
idiolect of that one female student carrying traces of egocentricity which indicates that the use of 'I' can neither be completely associated with male writing style nor can female writing style be considered devoid of the traces of egocentricity.

\section{Degree of Modality}

Modality, which refers to the use of modal verbs, is another area which manifests significant gender differences in writing. Modality "is often related to how plausible the speaker thinks it is that what the sentence expresses will actually happen" (Borjars \& Burridge, 2010, p. 134). The data provided in Table: 1(f) gives a clear picture of differences in the use of modals indicating the degree of certainty or/and uncertainty.

Table: 1 (f)

\begin{tabular}{|l|l|l|}
\hline $\begin{array}{c}\text { Frequency and nature of the } \\
\text { use of modals }\end{array}$ & Female Students & Male Students \\
\hline should & 50 & 14 \\
\hline may & 18 & 03 \\
\hline can & 22 & 17 \\
\hline must & 07 & 15 \\
\hline
\end{tabular}

It is clear from the data presented in Table 1(f) that the female students have used 'should' almost four times more than the male students. The females' tendency to use 'should' more frequently than males is indicative of the fact that females use hedges more than males. This is in accordance with the previous research data that female discourse is marked by the use of hedging showing signs of powerlessness in their language (Cameron, 2005; Lakoff, 1975; Tannen, 1996). The modal 'should' is used to make suggestions, while the use of 'must' indicates obligation. It is the use of 'must' that is found more frequently in male students' essay indicating the desire of males to assert power and authority. However, the male students did not use as many modals as the females did. In fact, the male students avoided the use of modals where possible by presenting their point of views as facts, while the female students used tentative style of discourse by employing modals like 'can' and 'may' besides 'should'. This difference in the frequency of the use of modals and the nature of the modals used is not just confined to writing but is also found in speech.

\section{Informative vs. Involved Style}

It is evident from the analysis of the topic choice and the use of first person pronouns that male students use informative style of discourse while female students' writing exhibit involved style of discourse. The female students' excessive use of 'we', for instance, is an act of engaging the readers in the discourse that is constructed through 
writing, whereas the high frequency of factual information in male students' writing manifests the informative style of discourse, which is in accordance with the male style of discourse.

\section{Conclusions}

The findings of this study reinforce the notion of gender performativity introduced by Butler (1990). There are enough clues available in students' writing to prove that the writers' gender identity is mediated through language unless there is a deliberate effort to conceal one's gender identity in written discourse. Although the results of the current study corroborate the findings of earlier research on gender differences in writing, particularly with reference to the differences in the frequency of spelling errors, use of the first person plural pronoun, syntactic complexity and the style of writing, the study also challenges some of the existing research data on language and gender which prevents the readers from making over generalizations and rigid compartmentalization based on gender differences. There is a need for a large corpus of data to be able to explore if the gender differences that have been identified are found in other female and male students' writing as well. The study has important pedagogical implications for language teachers as they need to understand these differences to be able to understand the diversity found in their learners' writing style in terms of gender differences and take this diversity as a challenge so that the teachers can design a separate set of strategies to help both the genders improve their academic writing.

\section{References}

Berninger V.W., Nielson K.H., Abbott R.D., Wijsman E. \& Radskind W. (2008). Gender Differences in Severity of Writing and Reading Disabilities. Journal of School Psychology, vol.46, pp.151-172.

Borjars, K. \& Burridge, K. (2010). Introducing English Grammar. (Second Edition). Great Britain: Hodder Education, an Hachette UK Company.

Boroomand, Abusaeedi \& Asghar (2013). A Gender-Based Analysis of Iranian EFL Learners' Types of Written Errors. International Journal of Research Studies in Language Learning, vol. 2:5, pp.79-92.

Browne, A. (1994). The Content of Writing in the Early Years: Issues of Gender. Reading, vol.28:3, pp.2-8. 
Butler, J. (1990). Performative acts and Gender Constitution: An Essay in Phenomenology and Feminist Theory. In S. Case (Eds.), Performing feminisms: Feminist critical theory and theatre, (pp. 270-282). Baltimore: Johns Hopkins University Press.

Cameron, D. (2005). Language, Gender and Sexuality: Current Issues and New Directions. Applied Linguistics, vol.26:4, pp.482 -502.

Chambers, J. C. (1992). Linguistic Correlates of Gender and Sex. English World -Wide, vol.13:2, pp.173-218.

Chen, J. F. (1996). Gender Differences in Taiwan Business Writing Errors. The Internet TESL Journal, vol.II:10. http://iteslj.org/.

Chiu, C. (2008). An Investigation of Gender Differences in EFL College Writing. Proceedings of the BAAL Annual Conference, pp. 25-26.

Deming, M. P. \& Gowen, S. G. (1990). Gender Influences on the Language Processes of College Basic Writers. Community/junior College Quarterly of Research and Practice, vol.14:3, pp.177-187.

Earl-Novell, S. (2001). 'Gendered' Styles of Writing and the 'Inequality in Assessment' Hypothesis: An Explanation for Gender Differentiation in First Class Academic Achievement at University, The International Journal of Sociology and Social Policy, vol.21:1/2, pp.160-173.

Jones, S. \& Myhill, D. (2007). Discourses of Difference? Examining Gender Differences in Linguistic Characteristics of Writing. Canadian Journal of Education, vol.30:2, pp.456-482.

Kanaris, A. (1999). Gendered Journeys: Children's Writing and the Construction of Gender. Language and Education, vol.13:4, pp.254-268.

Krashen, S.D. (1989). We Acquire Vocabulary and Spelling by Reading: Additional Evidence for the Input Hypothesis. Modern Language Journal, vol.73, pp.440-64.

Lakoff, R. T. (1975). Language and Women's Place. New York: Harper Colophon Books.

Morris, L.A. (1998). Differences in Men's and Women's ESL Writing at the Junior College Level: Consequences for Research on Feedback. The Canadian Modern Language Review, vol.55:2, pp.219-38. 
Pajares, P. \& Valiante, V. (2001). Gender Differences in Writing Motivation and Achievement of Middle School Students: A Function of Gender Orientation? Contemporary Educational Psychology, vol.26, pp.366-381.

Peterson S., \& Kennedy, K. (2006). Sixth Grade Teachers' Written Comments on Student Writing: Genre and Gender Influences. Written Communication, vol.23:1, pp.36- 62.

Peterson, S. (2002). Gender Meanings in Grade Eight Student's Talk About Classroom Writing. Gender and Education, vol.14:4, pp.351-366.

Peterson, S. (1998). Evaluation and Teachers' Perceptions of Gender in Sixth-Grade Student Writing. Research in the Teaching of English, vol.33:2, pp.181-208.

Roulis, E. (1995). Gendered Voice in Composing, Gendered Voice in Evaluating: Gender and the Assessment of Writing Quality. In D. L. Rubin (Ed.), Composing Social Identity in Written Language, (pp. 151-185). Hillsdale, NJ: Lawrence Erlbaum.

Saeed, A., Ramazan. M., Gujjar, A.A. \& Iqbal, J. (2011). Gender Differences and L2 Writing. Language in India, vol.11:7, pp.1-10. www.languageinindia.com. retrieved on Oct 3, 2015.

Shirzad, F., Musavi, K., Atmani, S., Ahranjani, K.A. \& Iraji, S. (2013). Gender Differences in EFL Academic Writing. International Journal of Academic Research, vol.5:4, pp.79-87. DOI: 10.7813/2075-4124.2013/5-4/B.11

Swann, J. (1992). Girls, Boys, and Language. Oxford: Blackwell Publishers.

Taha, H. (2006). Females' Superiority on Phonological and Lexical Processing. The Reading Matrix, vol.6:2, pp.70-79.

Tannen, D. (1996). Researching Gender-Related Patterns in Classroom Discourse. TESOL Quarterly, vol.30:2, pp.341-344.

Waskita, D. (2008). Differences in Men's and Women's ESL Academic Writing at the University of Melbourne. Journal of Socio-technology, vol.14:7, pp.448-463.

Younger, M., Warrington, M. \& Williams, J. (1999). The Gender Gap and Classroom Interactions: Reality and Rhetoric? British Journal of Sociology of Education, vol.20:3, pp.325-344. 
Prof. Dr. Kaleem Raza Khan is Ex. Chairman of the Department of English, University of Karachi.

Shumaila Shafket Ali is an Assistant Professor in the Department of English, University of Karachi. 